回回回回回回回回回回回回回回回回回回回回回回回回回

Problemy istorii, filologii, kul'tury 2 (2018), 44-62

(C) The Author(s) 2018

Проблемы истории, филологии, культуры 2 (2018), 44-62

(с)Автор(ы) 2018

\title{
A STUDY ON THE PREHISTORIC NON-OUTLINED HUMAN FACE ROCK ART IN CHIFENG AREA, CHINA AND THE APPLICATION OF MICRO EROSION DATING METHOD
}

\author{
Wu Jiacai \\ Inner Mongolia Normal University, Hohhot City, China \\ wujiacai321@sina.com
}

Abstract. A study on the rock art sites in twelve towns and villages near Chifeng in the recent 15 years was conducted and over 10,000 rock paintings and engravings were discovered. This paper focuses on the distribution and the shape of non-outlined human face petroglyphs. By using micro-erosion dating method and experiments on the samples with proper dating background, and the comparison research on the unearthed relics, the author acquired the dating data and concluded that the non-outlined human face rock art in Xiao Fengshan are dated to Neolithic age. The research has a fundamental meaning to the future research of the rock art dating in other areas.

Keywords: Hongshan, petroglyphs, human face image, dating, rock art sites

\section{INTRODUCTION AND HISTORY OF CHIFENG CITY}

\section{Location and history}

Located in the north of China, mid-east of Inner Mongolia Autonomous Region, Chifeng City is situated between the Yan Mountain and Greater Khingan Mountains. With a distance of $375 \mathrm{~km}$ from east to west and $458 \mathrm{~km}$ from south to north, it connects the Inner Mongolia plateau and Liaohe flatlands with a total area of 90,000 square kilometers. The geographical feature here is a complex and diverse one with mountains, plateaus, hills, basins, plains, deserts and lakes. Elevations decrease from 2,067 m $(6,781$ $\mathrm{ft})$ in the west to less than $300 \mathrm{~m}(980 \mathrm{ft})$ in the east. The coordinates of Chifeng city are $41^{\circ} 17^{\circ}-45^{\circ} 24^{\prime} \mathrm{N}, 116^{\circ} 21^{\prime}-120^{\circ} 58 \mathrm{E}$ (fig. 1). As it lies in the transitional area from the warm zone to the cold zone, it has a continental monsoon climate with distinctive season features.

In the northeast of Chifeng City, there is a red mountain, which was called Ulan Hada during the Mongolian Yuan period, meaning "a red mountain” (fig. 2, 1). In Qing

Wu Jiacai - director of China North Rock Art Research Institute, Honder College of Inner Mongolia Normal University.

Статья публикуется в рамках международного сотрудничества по проекту РФФИ 1809-00691.

Автор перевода с китайского - Т.Дж. Ричер (T.J. Richer)

C IA RAS, NMSTU, JHPhCS, 2018| DOI 10.18503/1992-0431-2018-2-60-44-62 
A Study on the Prehistoric Non-Outlined Human Face Rock Art in Chifeng Area 45

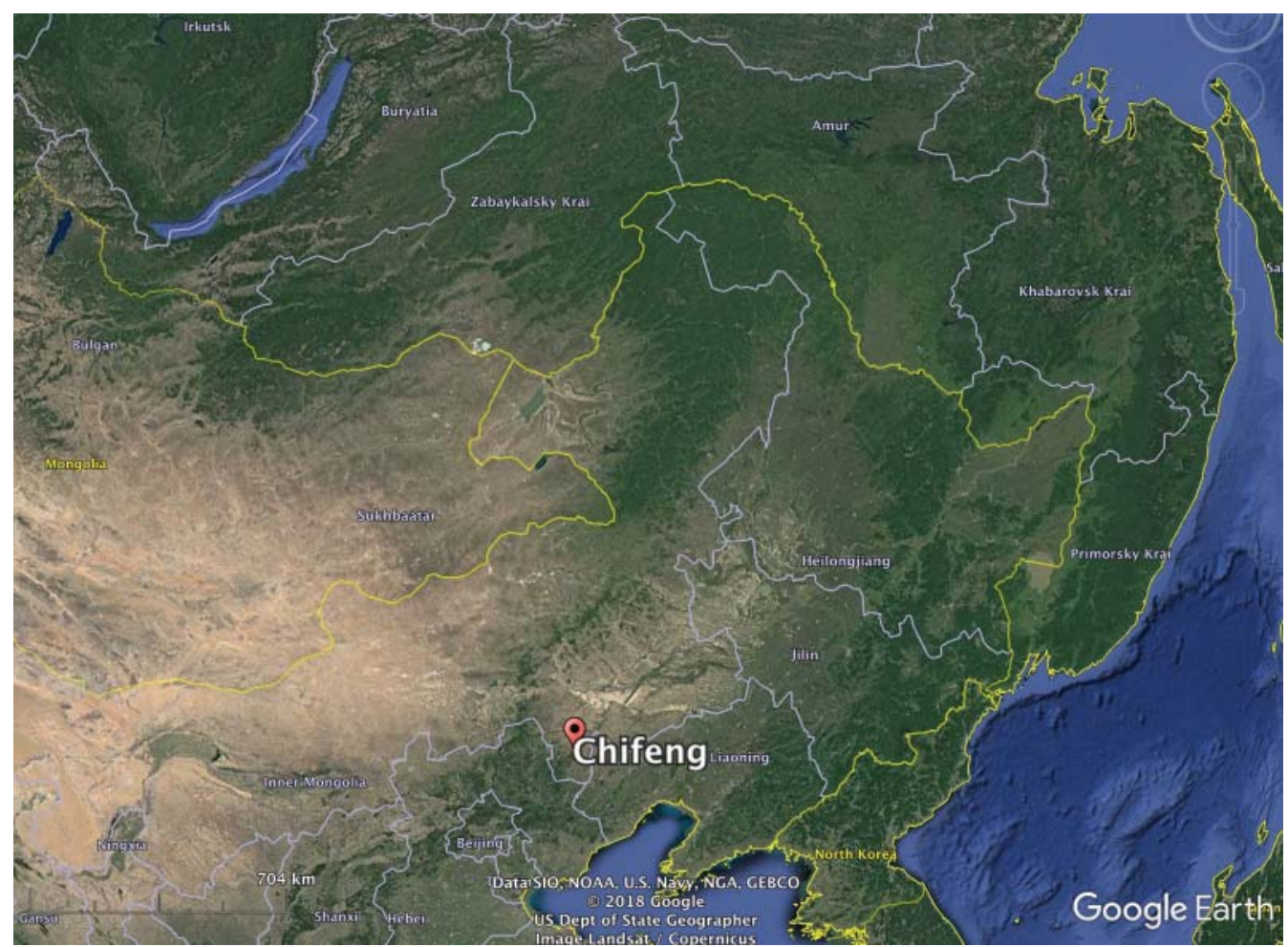

Fig. 1. Area under consideration

Dynasty, Zhaowu Da League was established at Gu Liulin, a place where 11 towns met. Therefore, it was named Zhaowu Da League, meaning hundreds of willows.

The historical cultures, which are named after the places of the respective archaeological discoveries, are as follows:

Shang Yao culture, 12,000 years BP;

Xiao Hexi culture, $12000-8300$ years BP;

Xing Longwa culture, 8300-7500 years BP;

Zhao Baogou culture, 7500-6500 years BP;

Hong Shan culture, 6500-5000 years BP;

Xiao Heyan culture, 5000-4300 years BP;

Lower Xia Jiadian culture, 4300-3500 years BP;

Upper Xiao Jiadian culture, 3500-2000 years BP;

Xia, Shang, Zhou dynasty-Liao, Jin, Yuan, Ming, Qing dynasty. features.

The unearthed cultural relics from various historical periods bear their unique

The research team spent 15 years exploring 12 towns and villages near Chifeng. During this time, over 10,000 rock engravings and paintings were found. The paper focuses on the distribution and the shape of non-outlined human face rock art, the application of the micro-erosion dating method and the comparative research on unearthed relics and non-outlined human face rock art. 


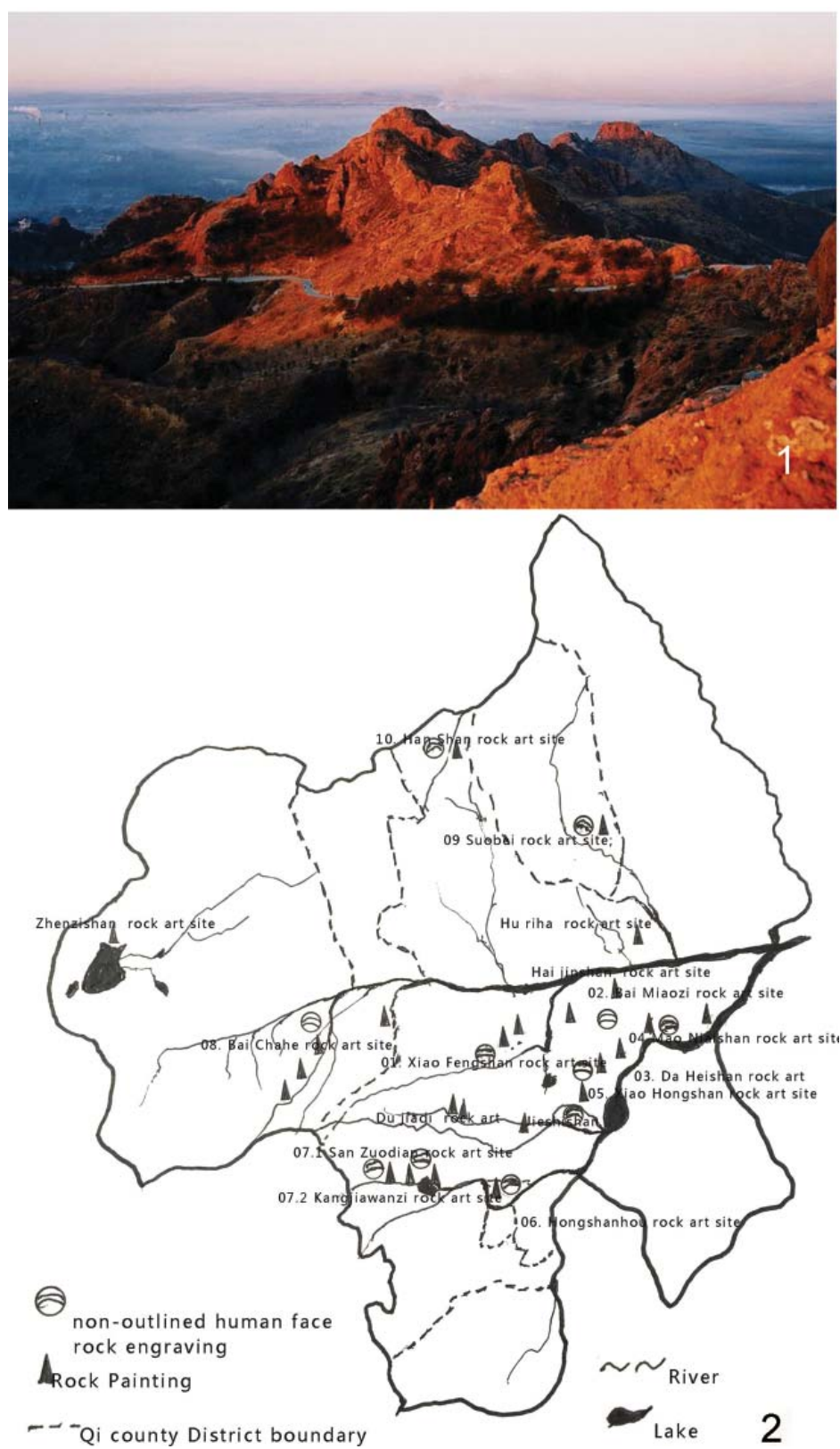

Fig. 2. Surroundings of the Chifeng City.

1 - in the north east of Chifeng City, there is a red mountain called Ulan Hada during Mognlia and Yuan period, which means "a red mountain"; 2 - distribution map of non-outlined human face rock art sites in Chifeng area: 01. - Xiao Fengshan rock art site; 02. - Bai Miaozi rock art site; 03. - Da Heishan rock art site; 04. - Maonaohai Shan rock art site; 05. - Xiao Hongshan rock art site; 06. - Hongshan Hou rock art site; 07. - Yin Hechuan rock art site; 07-1.-San Zuodian rock art site; 07-2. - Kangjiawanzi rock art site; 08. - Bai Chahe rock art site; 09. - Suobei Shan rock art site; 10. - Han Shan rock art site) 
A Study on the Prehistoric Non-Outlined Human Face Rock Art in Chifeng Area 47

\section{DISTRIBUTION AND SHAPE OF NON-OUTLINED HUMAN FACE ROCK ART}

The non-outlined human face petroglyphs from the Chifeng area are mainly distributed in the upper reaches of Laoha River and the Xilamulun River Valley. The 11 sites discovered are: (fig. 2, 2) 01. Xiao Fengshan rock art site; 02. Bai Miaozi rock art site; 03. Da Heishan rock art site; 04. Maonaohai Shan rock art site; 05. Xiao Hongshan rock art site; 06. Hongshan Hou rock art site; 07. Yin Hechuan rock art site; 07-1. San Zuodian rock art site; 07-2. Kangjiawanzi rock art site; 08. Bai Chahe rock art site; 09. Suobei Shan rock art site; 10. Han Shan rock art site;

Feature and information of non-outlined human face rock art in the Chifeng area $(01-10)$

01. Rock art site at Xiao Fengshan, Weng Niute Town, with 6 identifiable nonoutlined human face rock engravings. (fig. 3, 1). A statue of a 6,500-5,000 year-old "frog-shaped man" made of topaz was discovered in Lao Hushan Cave, 1 kilometer away from Xiao Fengshan (fig. 3, 5, 6).

02. Rock art site at Bai Miaozi, with 33 identifiable non-outlined human face rock engravings (fig. 4). Some cultural relics including a topaz axe, jade needle and jade sword of 6,000-5,000 years BP were unearthed at a place 5 kilometers away from the site. They are well preserved and now exhibited in the provincial museum.

03. Rock art site at Da Heishan, with 10 identifiable non-outlined human face petroglyphs (fig. 5, 1-2). A non-outlined human face petroglyph was found on the rock surface among 36 pictograms. Earlier non-outlined human face petroglyphswere covered by the pictograms and they could not be seen clearly until the researchers applied the paper rubbing technique.

04. Rock art site at Maonaohai Shan, with 5 identifiable non-outlined human face rock engravings (fig. 5, 3-4). The name "Maonaohai" originates from an ancient language used by the Dong Hu people. It means "a place to raise and train hunting dogs". The damaged part on the engraving was made during 204AD and 206AD when the ancient Xiongnu people launched an attack against the Dong Hu people. An essay written in Runi language was carved on the hills near Maonaohai Shan ${ }^{1}$.

05. Rock art site at Xiao Hongshan, with 3 identifiable non-outlined human face rock engravings (fig. 5, 5-6). The petroglyph was found at Xiao Hongshan near La Ha river, where a topaz statue of a "Sun God" of 6,500-5,000 years BP was unearthed (fig. 6, 1).

06. Rock art site at Hongshan Hou, with one identifiable non-outlined human face petroglyphs. In 1935, Hamada Kosaku, head of the Japanese Imperial University, excavated 36 tombs at the Hongshan Culture site, 1.5 kilometers north-east to the rock art site. In his book Chifeng Hongshan Hou edited by Hamada Kosaku, no rock art was mentioned.

07. Rock art site at San Zuodian, with two identifiable non-outlined human face petroglyphs (fig. 7, 1-2). They have been listed in the book Excavation Report on San Zuodian. Here they are classified as heritage of the lower Xia Jiadian Culture dating 4,300 years BP. However, the petroglyphs were found underneath a dwelling of the lower Xia Jiadian Culture and had been connected with the rocks beneath. This means

\footnotetext{
1 Wu 2008, 174; Tang 2008.
} 

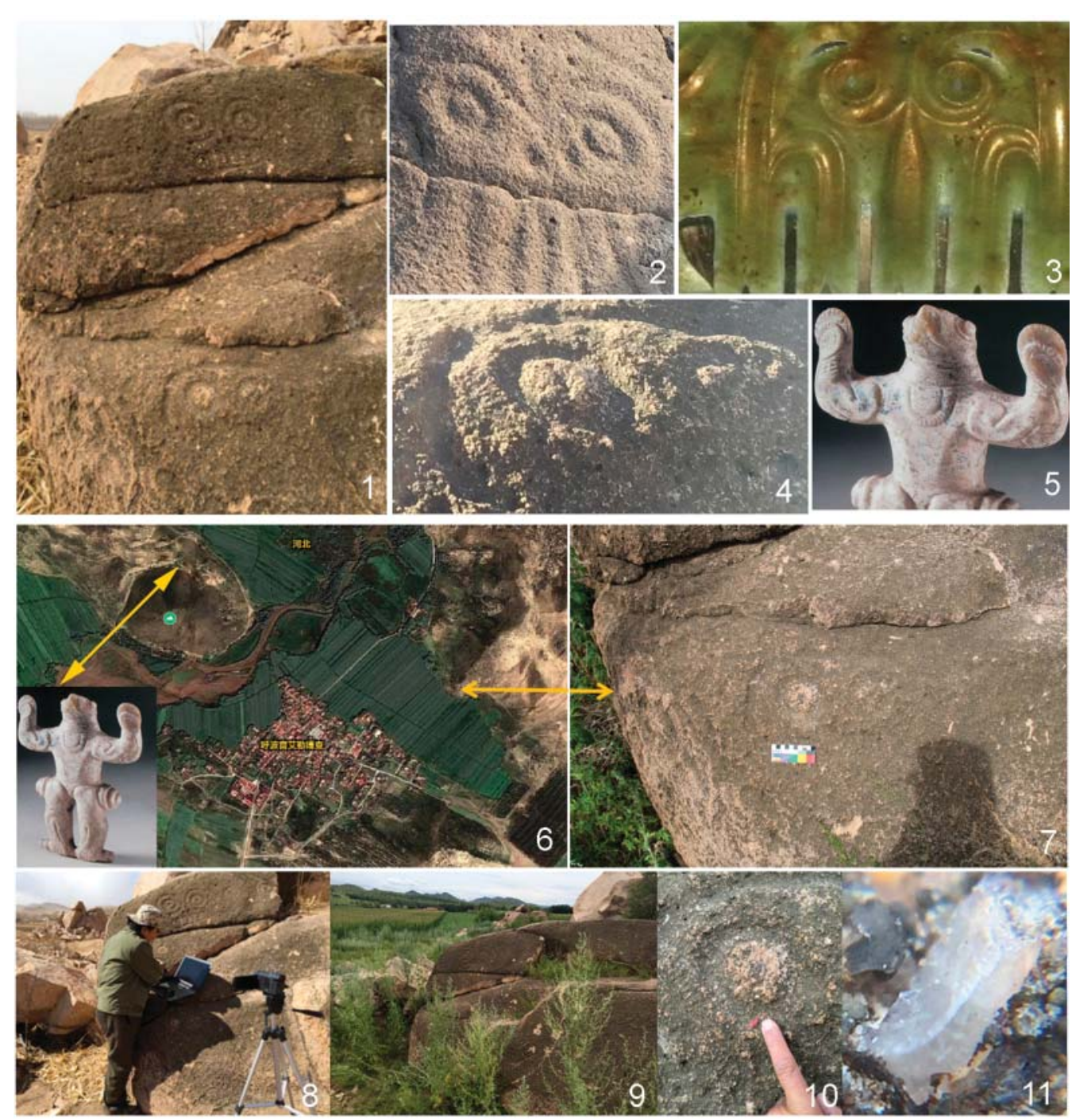

Fig. 3. Rock art in Xiao Fengshan, Weng Niute Town and analogues.

1 - rock art site in Xiao Fengshan, where some human face petroglyphswere discovered; 2 non-outlined human face petroglyph; 3 - the shape of eyes and beard of the hook cloud-shaped jade ornament $\left(5,120\right.$ years ago test by $\left.{ }^{14} \mathrm{C}\right)$, unearthed at Liang Hongshan culture site, Nei Niu river, Hongshan area, and non-outlined human face petroglyphs (fig. 3, 2) had some similarities and the processing technique seemed the same; 4 - the eyes of the engraving at the rock art site; 5 - the eyes of the topaz frog-shaped man (6,500-5,000 years ago), unearthed at Lao Hushan Cave 1 kilometer away from Xiao Fengshan rock art site, had some similarities to the eyes of the petroglyphs (fig. 3, 4); 6, 7 - Xiao Fengshan rock art site and the location of the sample; 8-10Xiao Fengshan rock art site, location of the sample; 11 - photo of quartz crystal sample 
A Study on the Prehistoric Non-Outlined Human Face Rock Art in Chifeng Area 49
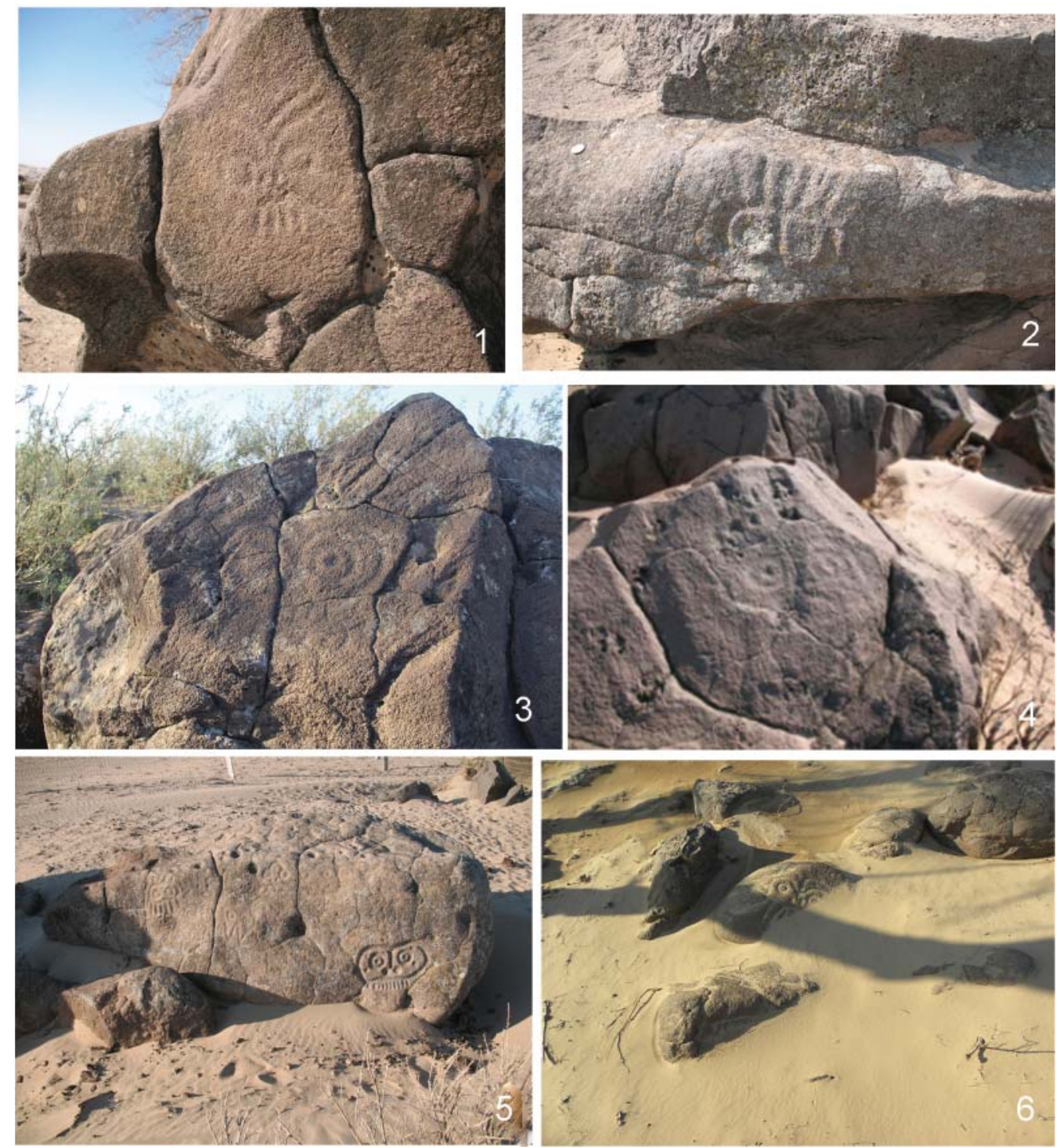

Fig. 4. Rock art (1-6) at Bai Miaozi, Weng Niute Town (petroglyphs were found in the desert) 

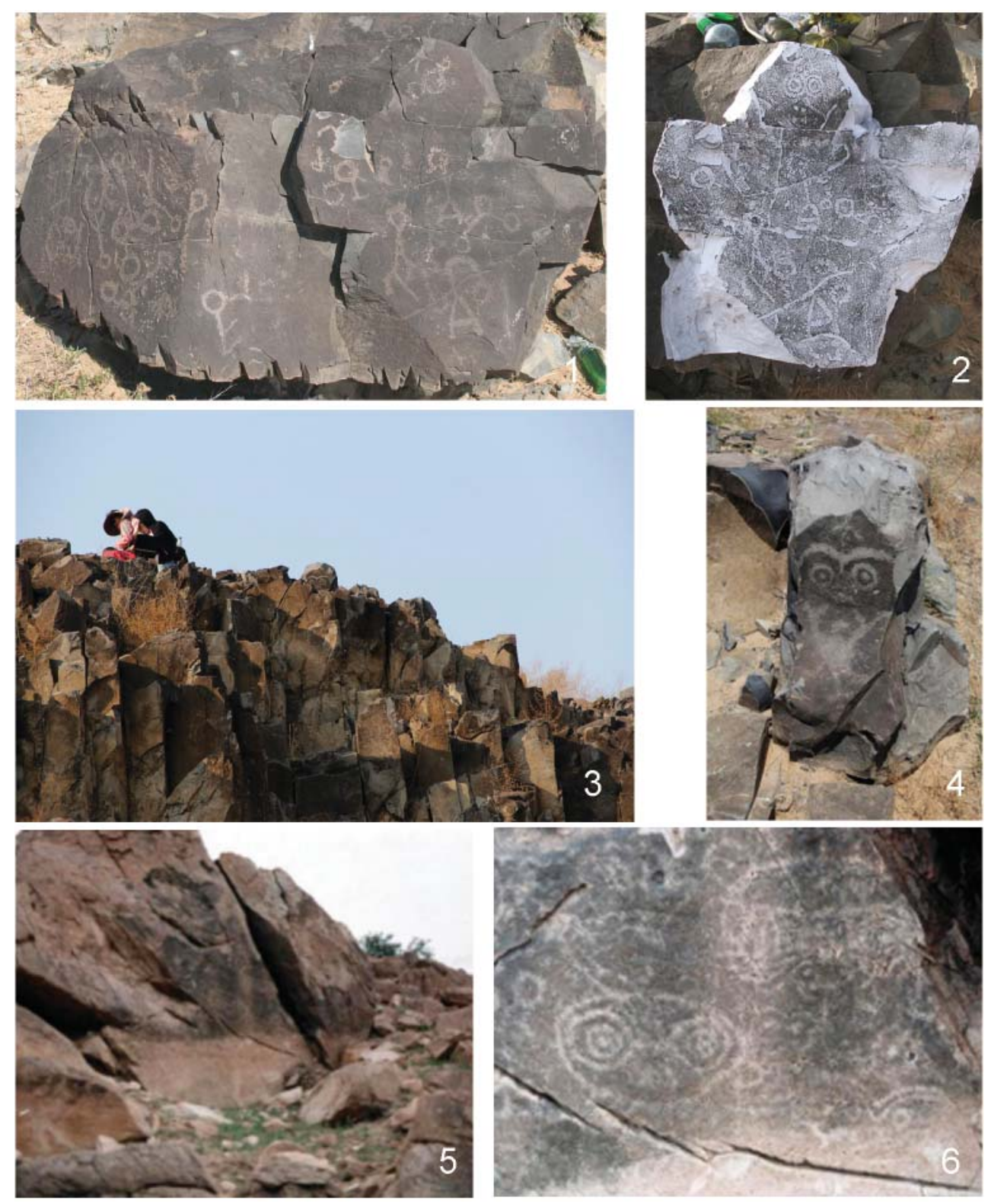

Fig. 5. Rock art sites.

1 - at Da Heishan, Weng Niute town (double engravings); 2 - paper rubbing of the early nonoutlined human face petroglyphs; 3, 4- at Maonaohai Shan, distant and close shot; 5, 6- at Xiao Hongshan, Weng Niute Town, distant and close shot 
A Study on the Prehistoric Non-Outlined Human Face Rock Art in Chifeng Area 51
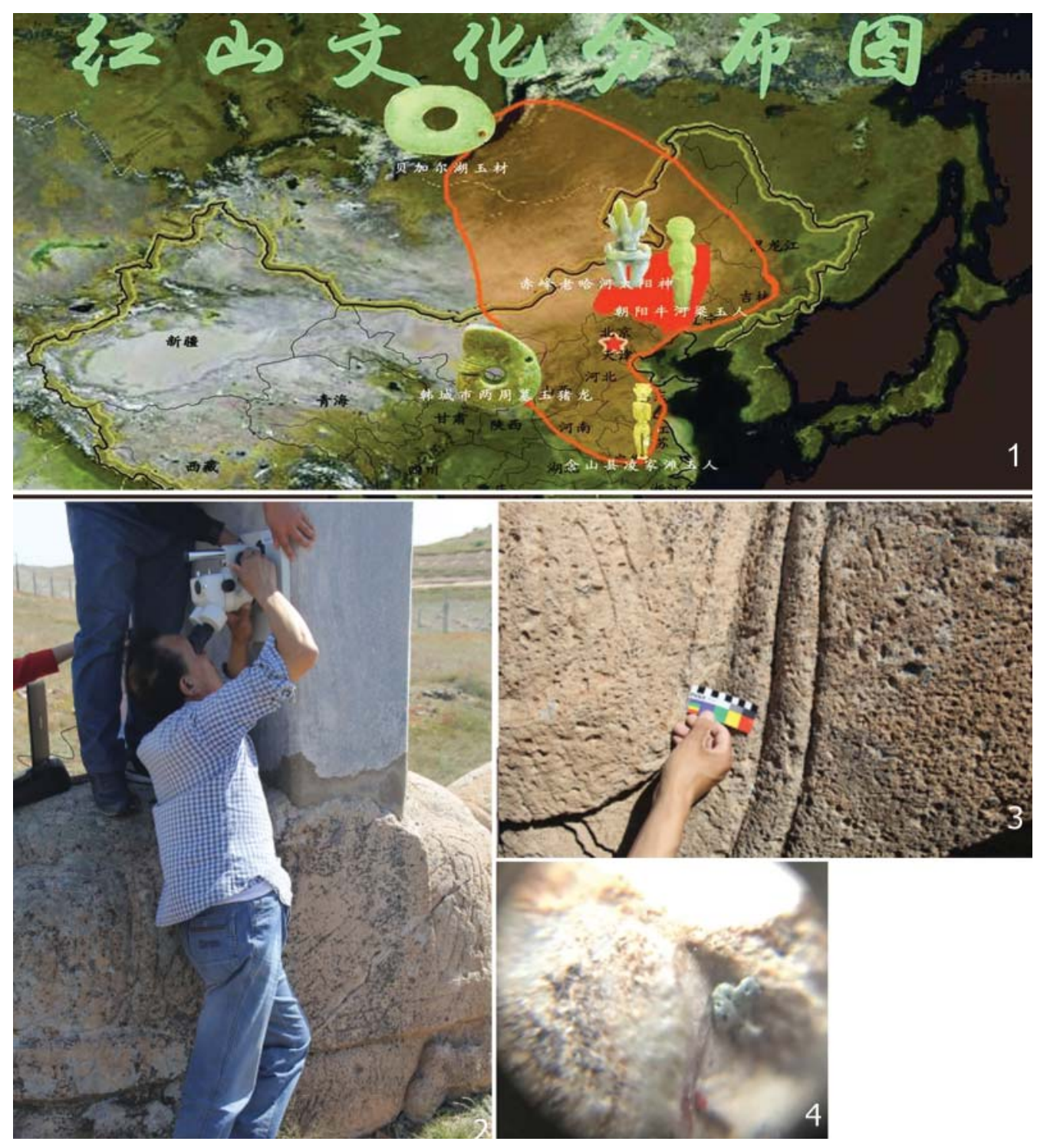

Fig. 6. 1 - the core and expansion area of the Hongshan Culture; 2 - microscope observation; 3, 4- sample data collection, international color scale correction and sample magnifying work 

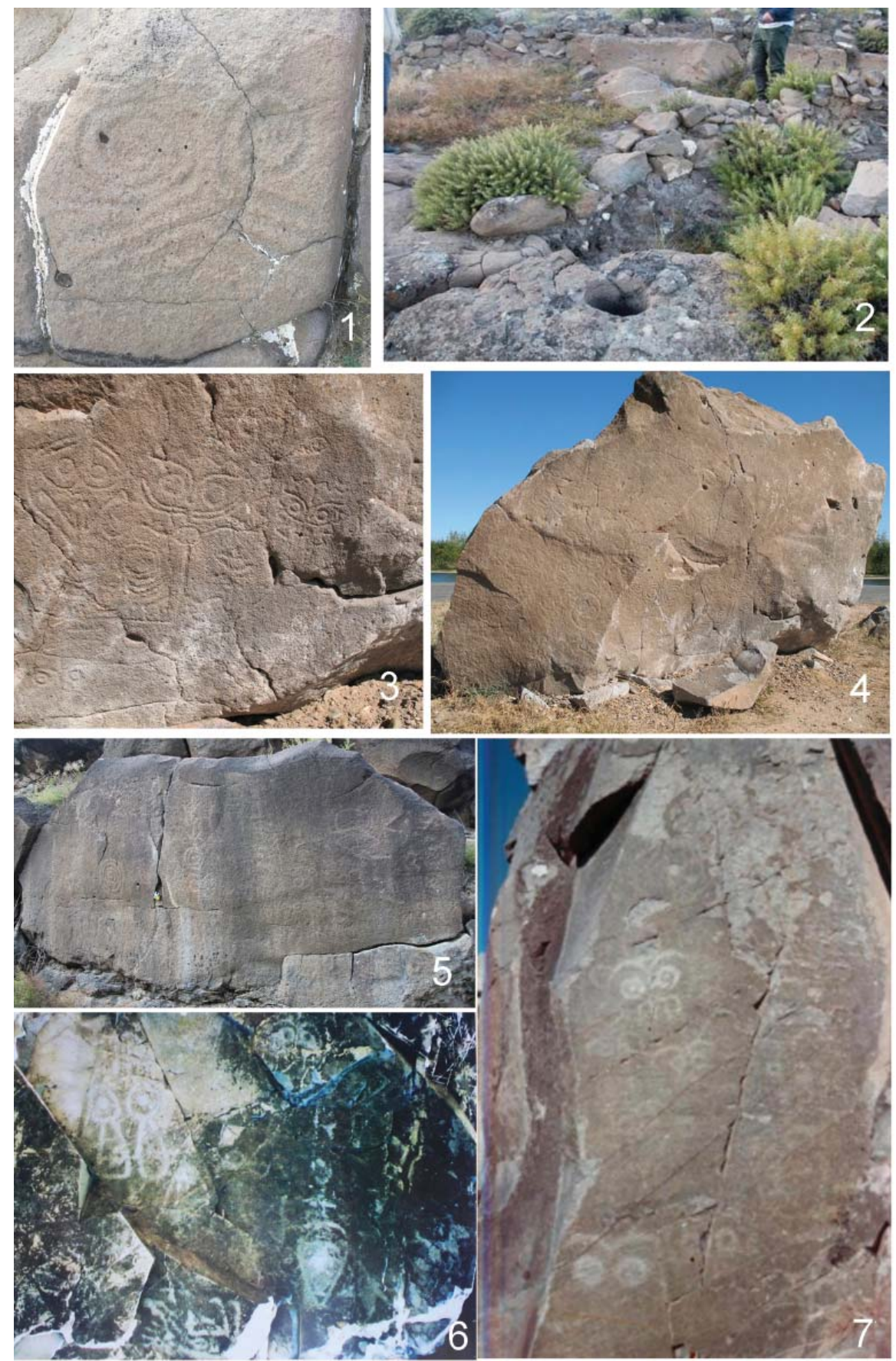

Fig. 7. 1 - rock art site at San Zuodian, Songshan area - human face petroglyphs; 2 - stone mortar and human face petroglyphs; 3, 4 - Kangjiawanzi rock art (close and distant shot); 5 rock art site at Ge Laoyingzi, Keshenketeng Town; 6 - rock art site at Suobei Shan, Balin Zuo Town; 7 - rock art site at Han Shan, Balin You Town 
A Study on the Prehistoric Non-Outlined Human Face Rock Art in Chifeng Area 53

that they had been there before the construction of the house and hence have a history of more than 4,300 years. Therefore, they belong to the Hongshan Culture.

07-2. Rock art site at Kangjiawanzi, with 11 identifiable non-outlined human face rock engravings (fig. 7, 3-4). Three engravings were moved to Hongshan Exhibition Center and displayed in the open air when the water dam at San Zuodian was constructed.

08. Rock art site at Ge Laoyingzi, with 2 identifiable non-outlined human face petroglyphs (fig. 7, 5).

09. Rock art site at Suobei Shan, with 1 identifiable non-outlined human face petroglyphs (fig. 7, 6).

10. Rock art site at Han Shan, with 6 identifiable non-outlined human face petroglyphs (fig. 7, 7).

\section{RESEARCH AND APPLICATION OF THE MICRO-EROSION DATING METHOD}

To date the non-outlined human face petroglyphs in Chifeng City, the researchers adopted different dating methods including Xanthoria elegans, ${ }^{14} \mathrm{C}$ and spectrum. The dates obtained from the above methods, however, varied greatly from the dates of the unearthed contemporary cultural relics. Therefore, the researchers studied the micro-erosion dating method from Rock Art Science by R.G. Bednarik ${ }^{2}$, and the micro-erosion method used by Professor Tang Huisheng when dating the Jiangjunya engravings. After purchasing the equipment used by R.G. Bednarik and learning the operations of the different processes in 2016 and 2017, the researchers organized a research team composed of members from the archaeological department, the History and Culture Institute of the Inner Mongolia Normal University, and members from the China North Rock Art Research Institute to conduct rock art research and experiments, and collect samples at the following sites: Xiao Jinggou at Da Qingshang in Hohhot, Xiao Fengshan, Bai Miaozi and Da Heishan in Weng Niute Town, San Zuodian in the Songshan area, Bai Chahe in Keshenketeng Town. A stele of Zhang Yingrui made in Yuan dynasty was used for data correction and the research team mainly conducted the micro-erosion dating method at the rock art sites of Xiao Fengshan and Xiao Jinggou. Thanks to the research team composed of scholars and experts from Australia, India and China, the team spent 15 days on the field (October $\left.3^{\text {rd }}-15^{\text {th }}, 2015\right)$ for research and sample collection needed for the micro-erosion data and other scientific research work, a solid foundation for the dating of the rock art at the two sites was laid. In the following, the research work done by the team will be introduced.

The rock art site of Xiao Fengshan is located north-east of Paozi Village, where "the oldest jasper dragon statue of China" was unearthed. 6 human-faced engravings and 21 cupules were found at the La Hushan, 1 kilometer north of the village. The place became also famous for the discovery in 1982 of a topaz frog-shaped man.

Hongshan Culture was put forward by Mr. Yin Da in his book Chinese Neolithic Culture $^{3}$. The book was published in 1955 and the preface was written by Chinese archaeologist Mr. Ling Yongsi. The Hongshan Culture discussed here has been studied by many scholars including Mr. Hamada Kosaku ${ }^{4}$, Director of the Japanese Imperial

\footnotetext{
2 Bednarik 2007.

3 Yin 1955.

4 Hamada 1938.
} 
University, in 1935, Mr. Torii Ryuzo, a Japanese archaeologist in 1908, Mr. E. Licent (French) and P. Teilhard de Chardin (French) in 1924, Mr. Liang Siyong, a Chinese archaeologist in 1930. Currently, the size of the Hongshan and related areas, where many cultural relics were unearthed, covers an area of 220,000 square kilometers with a diffusion area of over 200 square kilometers (Fig. 6, 1). The Xiao Fengshan rock art site was not known to the author until the 1980 s, when conducting a local history survey there. The site 34 kilometers north-east of the Xiao Fengshan rock art site was selected for studies by Mr. Robert Bednarik, Mr. Kumar, and Mr. Tang Huisheng. Bai Miaozishan. In the area $10 \mathrm{~km}$ northeast of the Xiao Fengshan rock art site, there was a Paleolithic human settlement site. A topaz frog-shaped man was discovered in Lao Hushan cave, 1 kilometer away from Xiao Fengshan. In 1972, a C-shaped jasper dragon statue was unearthed in an area 7 kilometers south of the Xiao Fengshan rock art site. In 1949, a C-shaped topaz dragon statue was unearthed at a site 26 kilometers north-west of the rock art site, and in the same year a topaz statue of a Sun God was unearthed 55 kilometers to the south. The above four unearthed cultural relics could be linked and dated to the Hongshang Culture period, i.e. about 6,500-5,000 years BP.

Six petroglyphs and 21 cupules in Xiao Fengshan were made of granite. By using a SMZ-143 microscope, the researcher found out that the rocks were rich in quartz crystal, which were suitable for micro-erosion sample collection and research.

Investigation at the Xiao Fengshan and Xiao Fengshan $35 \mathrm{~km}$ south of the Yuan dynasty Zhang Yingrui tablet, straining for observation, gained the stone loss data for correction. Fluoroscopy has the data of micro-corrosion data of chronograms and lithographs:

Research on the recorded stele and the micro-erosion data information

The stele of Zhang Yingrui was made on the surface of a big rock in Yuan dynasty (Shi Jinshan engraving rock in Dushu Village, Fangshan Town, Dadu), and the rock Bixi statue was made of siliceous limestone on Bai Yinchagan Hill, Qu Ningluluwang City, in Yuan dynasty. The location of the stele is N42 $48^{\prime} 4370$ E119 $03^{\prime} 5604$ and it faces south with an elevation of 780 meters. It was built in 1335 and it is 5.63 meters high, 1.37 meters wide, and 0.4 meter thick. The stone Bixi beneath the stele is 1.5 meters high, 1.37 meters wide, and 2.3 meters long with a simple but vigorous shape. By using a SMZ-143 microscope, the researcher found that the engraving side was rich in quartz crystal. The micro-corrosion method was used to measure the loss of crystal stone from a 90-degree angle. Without contamination through humans and animals, it was suitable for micro-erosion dating. In one engraved groove, the research used an HP computer connected with the hand-USB Microscope 1.3MPUSB2.0 and found quartz stone loss of $45.55 \mu \mathrm{m}$, with a width of $1.91 / 1.91 / 1.91 / 1.91 \mu \mathrm{m}$ and an average width of $=7.64 / 4=1.91 \mu \mathrm{m}$.

The first quartzite loss in the second place was $66 \mu \mathrm{m}$, with a wide range of $1.91 / 1.89 / 1.89 / 1.49 / 2.97$, and the weighted average width $=1.91 \mu \mathrm{m}$. Zhang Yingrui tablet straining series three years to 628 years ago (yuan) Quartz crystal with a 90 Angle micro-corrosion length and area measuring scale (EM electron microscope) micro-corrosion of the serial number L micro-corrosion width $\mathrm{W}$ micro-corrosion area S. 150.001 .9195 .5022 .701 .895 .1034 .051 .897 .65 All of them are 1.4910 .13 .5 $2.702 .978 .04 \sum 66.25$ to $126.25=126.25 / 66.25=1.91 \mu \mathrm{m}$ (tabl. 1$)$. 
A Study on the Prehistoric Non-Outlined Human Face Rock Art in Chifeng Area 55

\begin{tabular}{|l|l|l|l|}
\hline No & $\begin{array}{l}\text { Micro-corrosion } \\
\text { length }\end{array}$ & $\begin{array}{l}\text { Micro-corrosion } \\
\text { width }\end{array}$ & $\begin{array}{l}\text { Micro-corrosion } \\
\text { space }\end{array}$ \\
\hline 1 & 50.00 & 1.91 & 95.50 \\
\hline 2 & 2.70 & 1.89 & 5.10 \\
\hline 3 & 4.05 & 1.89 & 7.65 \\
\hline 4 & 6.80 & Average 1.49 & 10.13 \\
\hline 5 & 2.70 & 2.97 & 8.04 \\
\hline$\sum$ & 66.25 & - & 126.25 \\
\hline & $\sum_{n-5}^{\text {em }} w l / l=\mathbf{1 2 6 . 2 5 / 6 6 . 2 5}=\mathbf{1 . 9 1 u m}$ & \\
\hline
\end{tabular}

Table 1. Micro-corrosian data

The age coefficient is $\mathrm{ka}=2.8 \mu \mathrm{m}$ ( $\mathrm{ka}$ refers to 1,000 years, and $\mu \mathrm{m}$ refers to micron). Microscope observation, sample data collection, international color scale correction and sample magnifying work have been conducted by the researchers (fig. 6, 2-4).

Micro-erosion data of Xiao Fengshan rock art

The Xiao Fengshan rock art site is located at Jianyuan Hill, $1 \mathrm{~km}$ north-east of

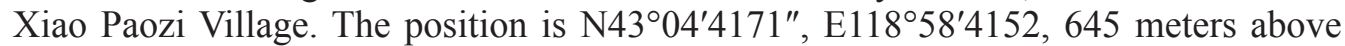
sea level. A long boulder of granite on a hillside slope was tested. There were six clearly identifiable human face petroglyphs on the surface of the boulder. The images were engraved with smooth grooves, and they were probably made with agate, flint, gravel and other tools. The rock was rich in quartz crystal, which met the condition to conduct micro-erosion dating. The research team came to the site five times (February $11^{\text {th }}, 2016$, April $1^{\text {st }}, 2016$, April $2^{\text {nd }}, 2016$, April $10^{\text {th }}, 2016$, July $23^{\text {rd }}, 2016$ ) to collect sample data at the left eye of the image. Ideal sample data was obtained after micro quartz crystals were captured successfully twice.

Tested by microscope, the micro crystal in the loss groove was shown at 35 degree against standing position, and it was in 90 degree through perspective testing (fig. 8, $1-2)$. After multiple times of magnifying, the size of the crystal was tested to be $280 \mu \mathrm{m}$ long and with a maximum width of $150 \mu \mathrm{m}$. On the surface of the loss micro crystal, with every 29 partitions, the loss length of the micro crystal was tested to be $191 \mu \mathrm{m}$, with a weighted average of $19.1 \mu \mathrm{m}$, a maximum width of $26 \mu \mathrm{m}$, and a minimum of $15 \mu \mathrm{m}$ (fig. 8, 1 ; tab. 2.1). 10 segments were divided from $15 \mu \mathrm{m}$ to $26 \mu \mathrm{m}$, (Table 2.2) and the proportion of the loss could be calculated. A higher proportion of the loss micro crystal would provide a higher accuracy rate. For time graph of micro-erosion of the quartz crystal at Xiao Fengshan rock art site, Chifeng, refer to fig. 9.

Calibration curve and micro-erosion date of the rock art 


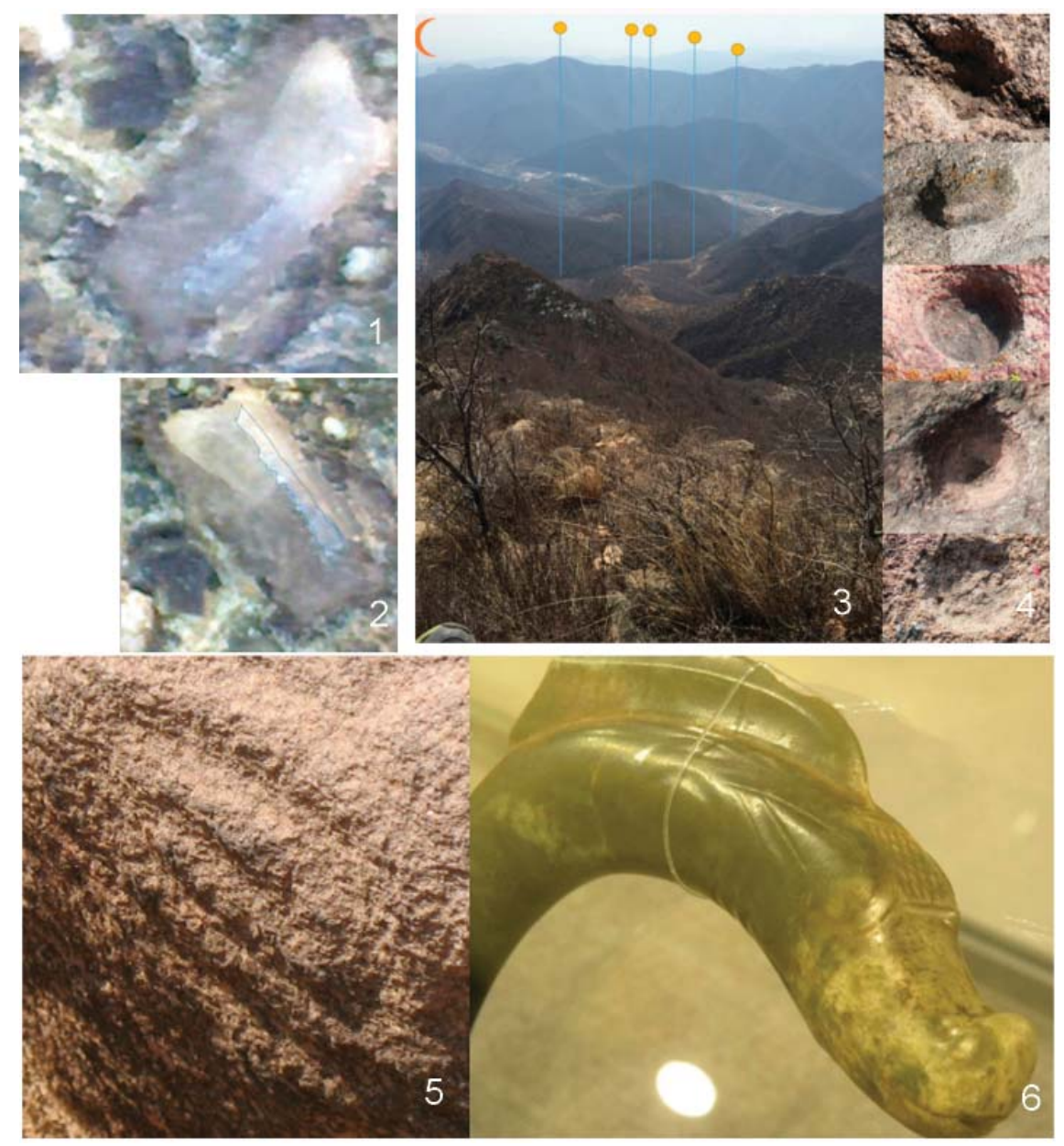

Fig. 8. 1, 2 - photo of eroded micro crystal under microscope; 3, 4- distribution and shape of rock art at Xiao Jinggou, Da Qingshan; 5 - a dragon face engraving at Ju Shuishi, Bai Miaozi; 6 - the eyes of C-shaped jasper dragon statue of 6,500-5,000 years ago

The loss micro crystal of the Zhang Yingrui stele from 1335 was tested to be 1.91 $\mu \mathrm{m}$ wide in average, and the erosion coefficient was calculated to be $2.8 \mu \mathrm{m} / \mathrm{ka}$. The researchers carefully examined the stele and confirmed it had been well preserved before using the micro-erosion coefficient as the calibration curve (Note: "E" is short for erosion. The test was conducted in 2017, so "till now" means till 2017). After calculation and calibration, the obtained result was as follows:

Micro-erosion date: E6821+2465/- 1464(n) BP

Factors affecting micro-erosion on the rock art in northern China: 1 Orientation of the rock art site; 2 - Location of rock groove; 3 - Disturbance through humans and animals; 4 - Sample accuracy. 
A Study on the Prehistoric Non-Outlined Human Face Rock Art in Chifeng Area 57

\begin{tabular}{|c|c|c|r|}
\hline $\begin{array}{c}\text { No of } \\
\text { partition }\end{array}$ & $\begin{array}{c}\text { Partition } \\
\text { width }\end{array}$ & $\begin{array}{c}\text { Partition } \\
\text { length }\end{array}$ & \multicolumn{1}{c|}{$\begin{array}{c}\text { Partition } \\
\text { space }\end{array}$} \\
\hline 1 & 17.2 & 5.3 & 91.2 \\
2 & 17.8 & 5.5 & 97.9 \\
3 & 16.5 & 6.0 & 99.0 \\
4 & 16.2 & 4.7 & 76.1 \\
5 & 15.2 & 4.3 & 65.4 \\
6 & 15.0 & 11.7 & 175.5 \\
7 & 15.2 & 5.8 & 88.2 \\
8 & 15.8 & 5.7 & 90.1 \\
9 & 19.5 & 7.5 & 146.3 \\
10 & 19.2 & 6.5 & 124.8 \\
11 & 17.7 & 5.0 & 88.5 \\
12 & 17.7 & 10.3 & 182.3 \\
13 & 18.3 & 11.3 & 206.8 \\
14 & 21.2 & 6.2 & 131.4 \\
15 & 16.7 & 4.7 & 78.5 \\
16 & 15.5 & 6.7 & 103.9 \\
17 & 16.0 & 9.3 & 148.8 \\
18 & 19.5 & 6.3 & 122.9 \\
19 & 21.8 & 5.3 & 115.5 \\
20 & 19.5 & 2.5 & 48.8 \\
21 & 18.5 & 6.5 & 120.3 \\
22 & 22.2 & 7.7 & 170.9 \\
23 & 22.3 & 6.7 & 149.4 \\
24 & 19.0 & 5.8 & 110.2 \\
25 & 22.3 & 8.0 & 178.4 \\
26 & 26.0 & 5.3 & 137.8 \\
27 & 25.3 & 6.5 & 164.4 \\
28 & 22.5 & 6.0 & 135.0 \\
29 & 24.7 & 7.5 & 185.3 \\
\hline $\boldsymbol{\Sigma}$ & 554.3 & $\mathbf{1 9 0 . 6}$ & $\mathbf{3 6 3 3 . 6}$ \\
\hline & & & \\
\hline
\end{tabular}

\begin{tabular}{|c|c|c|c|c|}
\hline \multirow[b]{2}{*}{\begin{tabular}{|c|} 
No of \\
partition
\end{tabular}} & \multicolumn{4}{|c|}{ Unit: $\mu \mathrm{m}$} \\
\hline & $\begin{array}{l}\text { Partition } \\
\text { width }\end{array}$ & $\begin{array}{l}\text { Partition } \\
\text { length }\end{array}$ & $\begin{array}{l}\text { Partition } \\
\text { space }\end{array}$ & $\begin{array}{c}\text { Rate } \\
\text { percent } \\
\text { age } \%\end{array}$ \\
\hline 6 & 15.0 & 11.7 & 175.5 & \\
\hline 7 & 15.2 & 5.8 & 88.2 & \\
\hline 8 & 15.8 & 5.7 & 90.1 & \\
\hline 5 & 15.2 & 4.3 & 65.4 & \\
\hline \multirow{2}{*}{16} & 15.5 & 6.7 & 103.9 & \\
\hline & & & 523.1 & 14.4 \\
\hline 3 & 16.5 & 6.0 & 99.0 & \\
\hline 4 & 16.2 & 4.7 & 76.1 & \\
\hline 15 & 16.7 & 4.7 & 78.5 & \\
\hline \multirow[t]{2}{*}{17} & 16.0 & 9.3 & 148.8 & \\
\hline & & & 402.4 & 11.1 \\
\hline 1 & 17.2 & 5.3 & 91.2 & \\
\hline 2 & 17.8 & 5.5 & 97.9 & \\
\hline 11 & 17.7 & 5.0 & 88.5 & \\
\hline \multirow[t]{2}{*}{12} & 17.7 & 10.3 & 182.3 & \\
\hline & & & 459.9 & 12.7 \\
\hline 13 & 18.3 & 11.3 & 206.8 & \\
\hline \multirow[t]{2}{*}{21} & 18.5 & 6.5 & 120.3 & \\
\hline & & & 327.1 & 9.0 \\
\hline 9 & 19.5 & 7.5 & 146.3 & \\
\hline 10 & 19.2 & 6.5 & 124.8 & \\
\hline 18 & 19.5 & 6.3 & 122.9 & \\
\hline 20 & 19.5 & 2.5 & 48.8 & \\
\hline \multirow[t]{2}{*}{24} & 19.0 & 5.8 & 110.2 & \\
\hline & & & 553.0 & 15.2 \\
\hline 19 & 21.8 & 5.3 & 115.5 & \\
\hline \multirow[t]{2}{*}{14} & 21.2 & 6.2 & 131.4 & \\
\hline & & & 246.9 & 6.8 \\
\hline 22 & 22.2 & 7.7 & 170.9 & \\
\hline 23 & 22.3 & 6.7 & 149.4 & \\
\hline 25 & 22.3 & 8.0 & 178.4 & \\
\hline \multirow[t]{2}{*}{28} & 22.5 & 6.0 & 135.0 & \\
\hline & & & 637.7 & 17.4 \\
\hline 29 & 24.7 & 7.5 & 185.3 & 5.1 \\
\hline 27 & 25.3 & 6.5 & 164.4 & 4.5 \\
\hline 26 & 26.0 & 5.3 & 137.8 & 3.8 \\
\hline$\Sigma$ & 554.3 & 190.6 & 3633.6 & 100.0 \\
\hline
\end{tabular}

Table 2.2

Table 2. Xiao Fengshan quartz crystal loss micro-transparency measurement data

Orientation of the rock art site. The researchers compared the rock engravings with the stele made in the same geographical environment and place. Both the rock art site and the stele are located in the middle of the valley, and surrounded by hills on three sides (fig. 10,1-2). The two quartz crystals tested had different orientations, so we collected sample data from the sunny side of the Bixi shoulder in case of value difference. If the geographical position was the same and the orientation of the crystals differed, the degree of the loss would not be the same, which could be testified after the study 


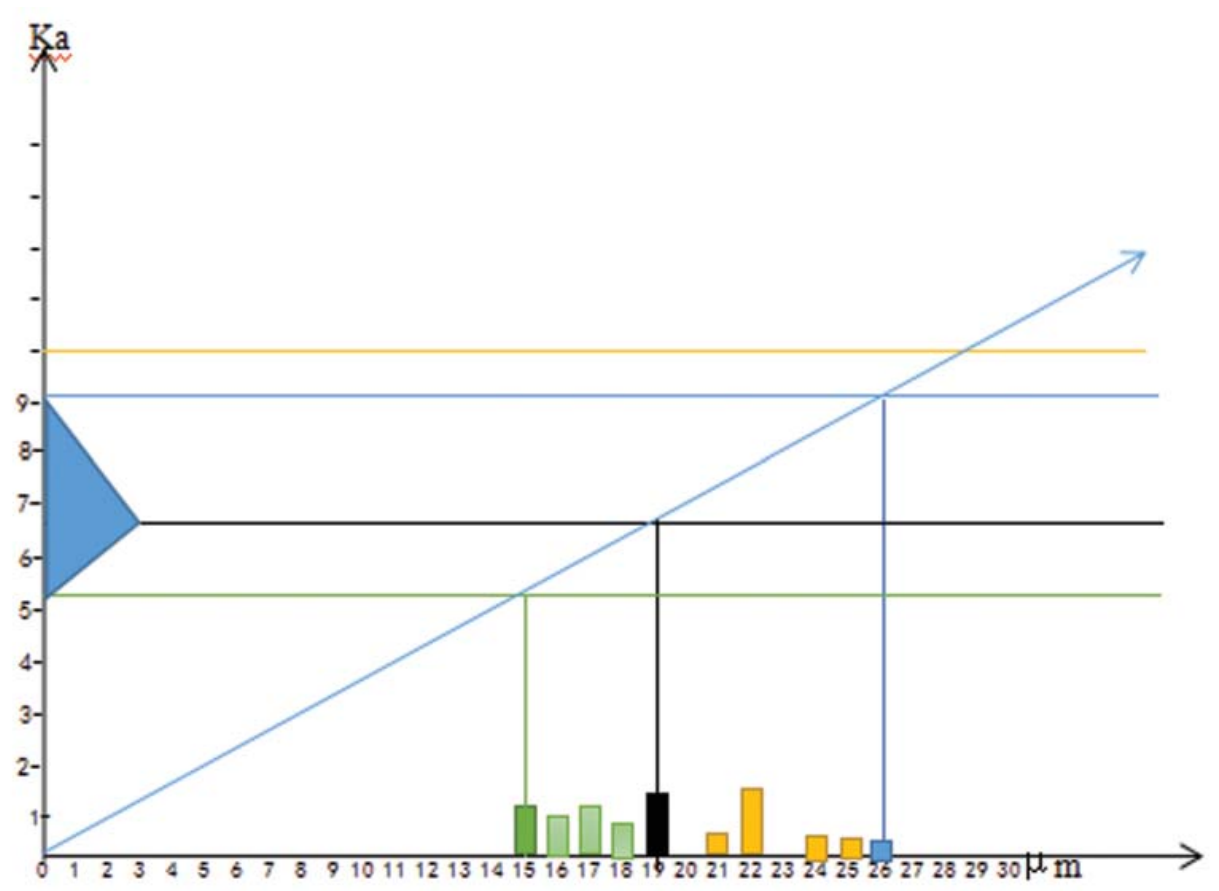

Fig. 9. Time graph of micro erosion of the quartz crystal at Xiao Fengshan Rock art site, Chifeng
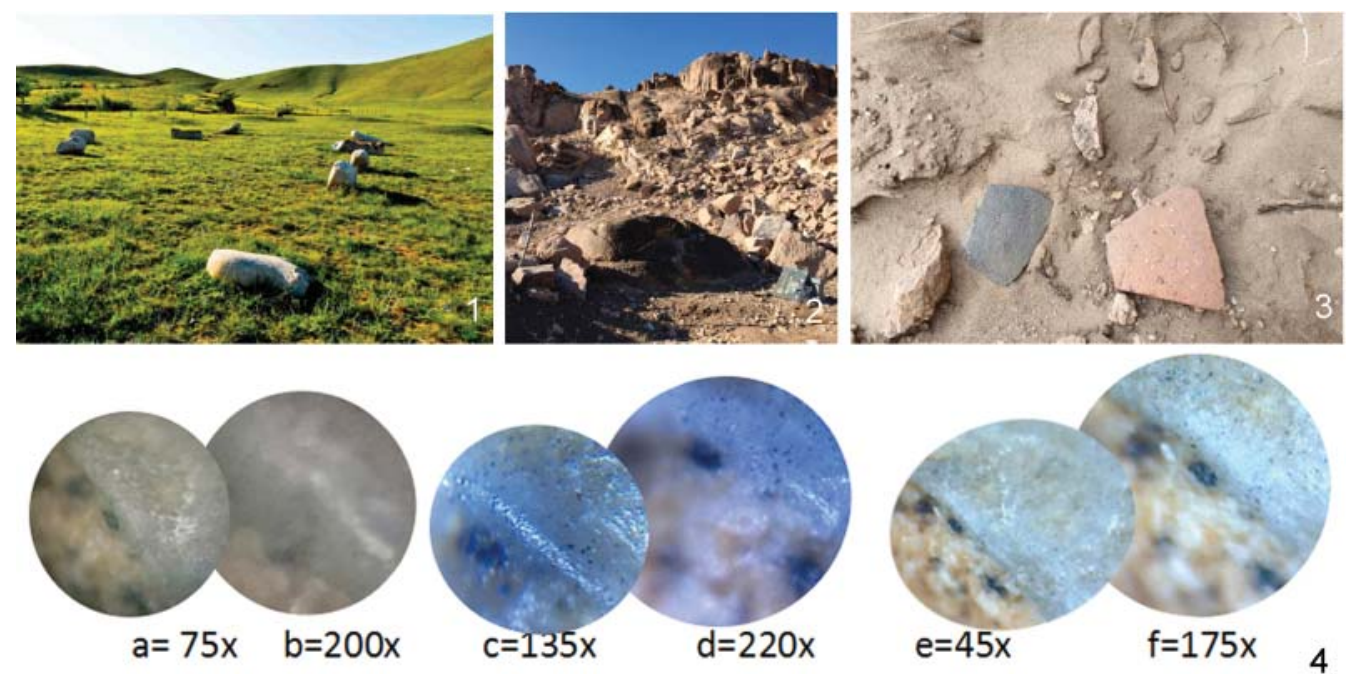

Fig. 10. 1, 2 - Zhang Yingrui stele and environment; 3 - Neolithic pottery remains at the rock art site; 4 - Zhang Yingrui tablet straining show 90 Angle of the micro crystal stone kui perspective: microcrystalline stone loss map of ab binocular microscope; the microcrystalline stone loss spectrum of CD binocular microscopy; the microscopic crystal loss map of Ef electron microscopy 
A Study on the Prehistoric Non-Outlined Human Face Rock Art in Chifeng Area 59

Location of rock groove. On October 4th, 2015, Robert, Kumar and Tang came to Hohhot to conduct a field research at Xiao Jingou, Da Qingshan. Two cupules were found at first and another 7 after the general study. The researchers collected microerosion data on 5 cupules to examine the loss degree of the rock (fig. 8, 3-4). The results showed that with different crystal positions, the value of the quartz crystal was different. The value was large at the side towards the northwest wind and small towards the lee side. Meanwhile, the location of the cupules at the open site of positions I, II, and III was different from the lee side, just as the value.

Disturbance through nature, human and animal activity. Two cupules out of nine at Xiao Jinggou were eroded, and the researchers collected crystal samples from a cupule where the mountain stream did not run across. Since the site was not in a high place, it was easily disturbed by humans and animals. The accuracy of the loss was therefore relatively poor compared with the well-preserved site.

Sample accuracy. The researchers collected sample data five times, however, due to the influence of wind, high and deep temperatures, exposure as well as preparation of the equipment, they were successful only two times.

\section{COMPARISON BETWEEN CHIFENG NON-OUTLINED HUMAN FACE ROCK ENGRAVINGS AND UNEARTHED CULTURAL RELICS FROM HONGSHAN CULTURE}

According to the cultural relic reports on the Hongshan Culture area ${ }^{5}$, the author did the following research:

There were some similarities between the eyes of $\mathrm{C}$-shaped jasper dragon statue dating 6,500-5,000 years BP and a dragon face petroglyph at Ju Shuishi, Bai Miaozi (fig. 8, 5-0).

The shape of eyes and beard between the C-shaped jade ornament (5,120 years BP, confirmed by ${ }^{14} \mathrm{C}$ dating) from Liang Hongshan Culture site, Nei Niu River, Hongshan area, showed some similarities to the non-outlined human face petroglyph. Furthermore, the processing technique seemed to be the same (fig. 3, 2-3).

The eyes of the topaz frog-shaped man $(6,500-5,000$ years BP) unearthed at Lao Hushan Cave 1 kilometer away from Xiao Fengshan rock art site, and the eyes of the engraving at the rock art site showed some similarities (fig. 3, 4-5).

The upper edge of the colored pottery bowl $(6,500-5,000$ years BP) unearthed at Dong Shanpo, 200 meters away from Xiao Fengshan rock art site, was made of the same material as the colored pottery bowl (right photo) made during the Hongshan culture period (fig. 11).

\section{SUMMARY}

Human face petroglyphs are mainly distributed in the center of Chifeng. According to the survey, non-outlined and outlined human face petroglyphs are mainly distributed in the areas of Xi Lamulun River and La Ha River, that is, Weng Niute Town and the Songshan area. After studying the series of North Rock Art Publications, the animal engravings take a higher proportion in the west while human face petroglyphs and

\footnotetext{
${ }^{5}$ Liaoning Provincial Institute... (ed.) 1998, 2012; Archaeological Institute... (ed.) 2007; Wu 2007; Wu 2008; Guo 2010.
} 


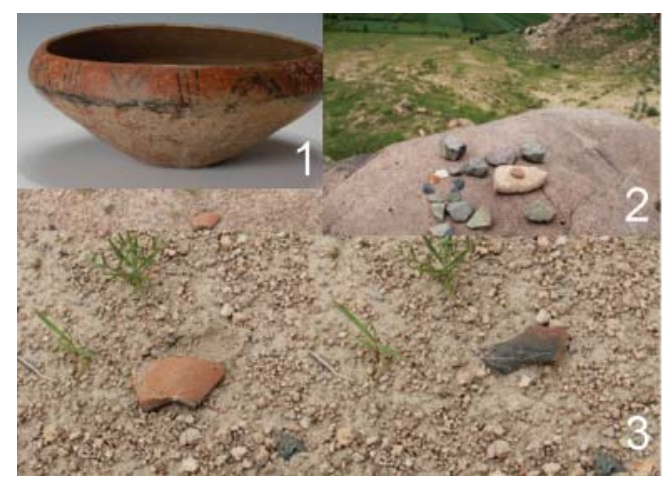

Fig. 11. 1 - colored pottery bowl made during the Hongshan culture period; 2 - stoneware collected at the site; 3 - the upper edge of the colored pottery bowl $(6,500-5,000$ years BP) unearthed at Dong Shanpo, 200 meters away from Xiao Fengshan rock art site, was made of the same material like the colored pottery bowl ( $(1)$

\begin{tabular}{|l|l|l|l|}
\hline \multicolumn{5}{|c|}{$\begin{array}{c}\text { The proportion of animal rock engravings } \\
\text { in different regions of northern China }\end{array}$} \\
\hline & Total of rock engravings & Animals & $\%$ \\
\hline Yinshan & 755 & 416 & 55.1 \\
\hline Damaidi & 835 & 677 & 81.1 \\
\hline Helanshan & 697 & 463 & 66.4 \\
\hline Mandela & 403 & 337 & 83.6 \\
\hline Wulanchabu & 1421 & 1104 & 75.0 \\
\hline $\begin{array}{l}\text { Wengniute } \\
\text { Songshan }\end{array}$ & 310 & 30 & 9.70 \\
\hline Ke Shenketeng & 71 & & \\
\hline Xinjiang & 1651 & 65 & 91.5 \\
\hline
\end{tabular}

Table 3. Percentage of animal rock paintings in different regions of the north

pictogram engravings take a higher proportion in the center and east (Table 3). As in the case of the Songshan area, Weng Niute Town, the proportion of human face engravings and pictogram engravings has reached $90.3 \%$.

The researchers collected samples on 10 non-outlined human face petroglyphs without damaging them, but only one engraving and the stele of Zhang Yingrui contained quartz crystal, while the rest was not qualified to be tested with micro-erosion. To obtain an accurate value, the researchers repeatedly tested the sample data and adopted point to area measurement at the dense part for the micro-erosion crystals as well as improved the weighted average. 
A Study on the Prehistoric Non-Outlined Human Face Rock Art in Chifeng Area 61

Steps: use of the electronic reading vernier micro crystal corrosion in binocular microscope measurement there are clearly marked as shown in figure a. Then corrosion of micro crystal by electron microscope and computer connection perspective, the ratio of the ab can amplify actual multiples. Collection of different angles of micro crystal corrosion perspective mapping on the computer to establish electronic microscope crystal stone kui samples basket of surveying and mapping, surveying and mapping error in order to avoid, we use a binocular microscope, binocular microscope, electron microscope, mobile phone microscope perspective of surveying and mapping

Zhang Yingrui tablet straining of the quartz crystal apply different microscopic perspective of micro crystal stone kui map), in the stone specimens of surveying and mapping in the basket, mapped the difference degree of stone kui measurement. After repeated verification of its surveying and mapping scale, the relevant data of each surveying and mapping point is registered. Zhang Yingrui tablet straining show 90 angle of the micro crystal stone kui perspective. Note: microcrystalline stone loss map of ab binocular microscope; the microcrystalline stone loss spectrum of $\mathrm{CD}$ binocular microscopy. The microscopic crystal loss map of Ef electron microscopy. $\mathrm{X}$ is a multiple (Fig. 10, 4).

The geographical conditions of the 11 non-outlined human face rock engravings in Chifeng varied greatly. Some engravings were located in the desert, some near rivers or mountains, and some in the swamp, with different ages and shapes. It was at Xiao Fengshan that the researchers successfully collected the sample data. By using microerosion dating method and comparison against the cultural relics unearthed there, the author concluded that the rock art in Xiao Fengshang should be attributed to Hongshan Culture, Neolithic age $(6,500-5,000$ years BP), and that the result matched with the micro-erosion dating method.

\section{REFERENCES}

Archaeological Institute of the Chinese Academy of Social Sciences, Research Centre for Chinese Archaeology and Art of the Chinese University of Hong Kong (ed.) 2007: Research and catalogue of Xinglongwa Culture Jade Ware [Xinglongwa Wenhua yuqi yu tulu]. Hong Kong. (In Chinese).

Bednarik, R. 2007: Rock Art Science. New Delhi.

Guo, D.Sh. 2010: Appreciation of Hongshan Culture jade ware [Hongshan wenhua yuqi jianshang]. Wenwu Press. (In Chinese).

Hamada, K., Mizuno, S. 1938: Chifeng Hongshan Hou [Chifeng Hongshan Hou]. Archaeologia Orientalis. Far-Eastern Archaeology Society of Japan 9. (In Japanese).

Liaoning Provincial Institute of Cultural Relics and Archaeology (ed.) 1998: Danangou - Excavation report of the Hou Hongshan Culture Cemetery [Danangou - Hou Hongshan Wenhua mudi fajue baogao]. Beijing. (In Chinese).

Liaoning Provincial Institute of Cultural Relics and Archaeology (ed.) 2012: Archaeological excavation report of the Niuheliang Hongshan Culture site [Niuheliang Hongshan wenhua yizhi kaogu fajue baogao]. Kexue Press. (In Chinese).

Tang, H.Sh. 2008: Discussion of the periodization and related questions of the prehistoric Jiangjunya rock engravings [Jiangjunya shiqian yanhua yizhi de duandai ji xiangguan wenti de taolun]. Dongnan Wenhua 2. (In Chinese). 
Wu, H.T. 2007: Hongshan Jade Ware [Hongshan yu qi]. Published by Taiwan Zhendan Museum. (In Chinese).

Wu, J.C. 2008: Hongshan rock engravings [Hongshan yanhua]. Neimeng Wenhua Press. (In Chinese).

Yin, D. 1955: Chinese Neolithic Culture. Zhongguo Xin Shiqi Wenhua 10. Sanlian Publishing House. (In Chinese). 